\title{
Developing Concepts of the Synapses
}

\author{
John C. Eccles \\ Max-Planck-Institut für Biophysikalische Chemie, Göttingen, Federal Republic of Germany, and CH 6646, Contra, Ticino, \\ Switzerland $1 \mathrm{H}, 52$
}

In this essay I provide a historical account of my experiences of neurophysiology over more than 60 years. I will attempt to portray the development of concepts in the light of successive achievements by experimental investigators. Finally, I will imagine possible developments in the future. Necessarily, I will restrict the scope of my review to fields in which I have a special interest, beginning with Sherrington, whose concepts provided the foundation of modern neurophysiology.

\section{Sherrington on the Synapse}

Sherrington's great book The Integrative Action of the Nervous System (1906) presented studies on a wide variety of spinal reflexes. Conduction in spinal reflexes was distinguished from conduction in nerve trunks by criteria that would be recognized today. For example, in spinal reflexes conduction is dramatized by a delay resulting in longer latency, irreversibility, temporal summation, and greater susceptibility to anoxia and to drugs. Sherrington attributed these differences to the interpolation in a reflex arc of a synapse, the nexus between neuron and neuron. So the study of reflexes was a study of neuronal connectivities with synapses as the key structures. Figure 1 shows a simplified diagram of various reflex pathways in the cat spinal cord with the synaptic actions, both excitatory and inhibitory, being evoked by input from a cutaneous afferent.

The brain was then regarded as the great neuronal network composed of distinct elements connected by synapses envisaged by Cajal, rather than as the reticulum envisaged by Golgi. The morphology of neurons was known by light microscopy, but the detailed structure of the synapse remained unknown until it was revealed by electron microscopy in the mid-1950s. It was recognized that there was much complexity at the higher levels of the brain. So, for several decades work was concentrated on the simpler nervous system of the spinal cord.

Sherrington's great contributions were made by recording reflex muscle contractions by techniques that he progressively improved. When I arrived in his laboratory in 1925, the research rooms were equipped with optical isometric myographs whose readings were recorded on moving photographic plates. Thanks to his analytical mind, Sherrington had recognized that all muscle contractions were the responses of motor units, each unit being composed of the motoneuron, its axon, and the set of about 100 muscle fibers that it innervated more or less exclusively. In the 1920s there developed precision in the study of reflex responses of the spinal cord of the unanesthetized, decerebrate or spinal cat. Interactions of reflex responses were

\footnotetext{
Correspondence should be addressed to John C. Eccles, CH 6646, Contra, Ticino, Switzerland $1 \mathrm{H}, 52$.

Copyright (C) 1990 Society for Neuroscience $0270-6474 / 90 / 123769-13 \$ 03.00 / 0$
}

understood as facilitation, occlusion, and inhibition, which were measured relative to numbers of motor units.

In 1925 Sherrington had developed a theory of synaptic actions, both excitatory and inhibitory, which assumed them to be very different from the all-or-nothing nerve impulses. These actions were localized at synaptic sites on neurons and, compared to nerve impulses, had a much longer duration ranging from 10 to $20 \mathrm{msec}$. The concepts of central excitatory and inhibitory states (c.e.s. and c.i.s; Creed et al., 1932, Chapters 3 and 6) were used to explain the central summation and subtraction of reflexes and the antagonistic effects of inhibitory inputs. For more than 2 decades these concepts provided the basis of our thinking and experimenting on synaptic actions. These ideas were eventually assimilated into the postsynaptic potentials revealed by intracellular recording. The pioneering concepts of Sherrington about synapses proved to be essentially correct but, as we shall see, an immense overlay of discoveries had meanwhile complicated the subject.

\section{The Oxford School}

It is important to realize that until the late 1920 s the experimental techniques of neurophysiology were restricted to mechanical recordings of reflex muscle contractions. At that time began the electrical recording of reflex responses in nerve or muscle, first by means of a string galvanometer (Creed et al., 1932 , Chapters $3-6$ ), later in the early 1930 s by amplifiers feeding into the Matthews mechanical oscilloscope, and finally by amplifiers feeding into the cathode ray oscilloscope.

The simplest reflex responses of the spinal cord were produced by the impulses from the large afferent fibers (called Ia) excited by the stretch of muscle spindles. Paul Hoffmann (1922) first recognized that in the familiar knee jerk reflex, afferent fibers from muscle excited motoneurons monosynaptically. Because of this discovery, the H-reflex was named after him in the 1940s. Sherrington and associates (Creed et al., 1932, Chapter 4) studied in detail the reflex responses that were evoked by stretching muscles, the "postural tone" of clinical neurology. Electrical recordings, by Denny-Brown (1929) and by Adrian and Bronk (1929), demonstrated that postural reflexes were due to repetitive motoneuronal discharges. These reflexes were extensively investigated in the late 1920 s and early 1930 s.

\section{Transmission at Synapses}

In the 1930s there was much interest in the mechanism of synaptic action, both excitatory and inhibitory. Synaptic transmission had been shown by Loewi in 1921 to be chemical for the inhibitory action of the vagus nerve on the heartbeat. Such transmission was eventually identified as being mediated by acetylcholine (ACh). Brown and I (Brown and Eccles, 1934) showed that an extraordinarily long delay of about $100 \mathrm{msec}$ intervened between vagal nerve impulses and the onset of slow- 


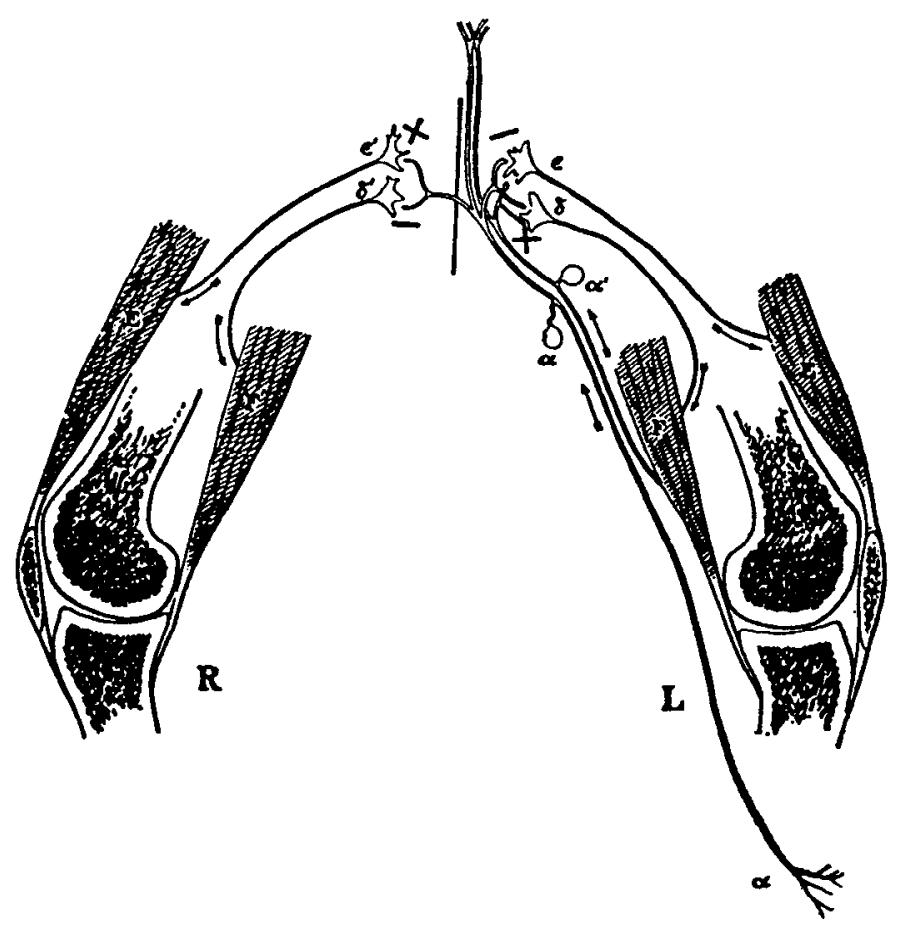

Figure 1. Flexor and extensor muscles of the knee-joint on right $(R)$ and left $(L)$ sides and of inputs to the spinal cord by a cutaneous afferent $(\alpha)$ and a muscle spindle afferent $(\alpha)$. The postulated reflex pathways show a flexor $(F)$ activation $(+)$ and an extensor $(E)$ inhibition $(-)$ ipsilaterally and an $F$ inhibition $(-)$ and $E$ activation $(+)$ contralaterally (Sherrington, 1906).

ing of the cardiac pacemaker. This delay indicated an extreme slowness of chemical synaptic transmission. A similarly long delay was also found for the neural accelerators of the pacemaker. Hence, there arose the concept that the very brief synaptic delays of less than $1 \mathrm{msec}$ observed for neuromuscular transmission and of about $3 \mathrm{msec}$ for ganglionic synaptic transmission were due to electrical transmission across the synapse. Such postulated electrical transmission was modeled with various arrangements of nerve fiber contacts, which were called "ephapses."

Between 1933 and 1936 Dale and his associates (Dale, 1937) showed conclusively that chemical transmission occurred also at neuromuscular synapses and at neuronal synapses of sympathetic ganglia, mediated by the ACh liberated from the presynaptic nerve terminals by nerve impulses. A compromise hypothesis was then put forward, namely, that there occurs an initial fast phase of electrical transmission followed by a slow phase of chemical transmission (Eccles, 1936). Eventually this electrical hypothesis was abandoned as well (Eccles et al., 1943) as a consequence of precise pharmacological study of the endplate potential in curarized muscle. A complete explanation of neuromuscular transmission was provided by ACh delivered to the muscle as a brief jet released by the presynaptic impulses. That simple explanation concealed a multitude of problems, however. At neuromuscular synapses $\mathrm{ACh}$ works by its nicotinic action, which, as will be discussed below, is a fast ionotropic transmitter, opening ionic channels (Fig. $2 A$ ). By contrast, at the heart $\mathrm{ACh}$ works by its much slower muscarinic action (Fig. $2 B$ ). This difference was not known in the 1930s, which is why the controversy of chemical versus electrical transmission at- tracted so many participants. The controversy lingered on for synapses in the CNS because no suitable candidate for chemical transmission had been discovered, and various ephaptic models had been proposed for either excitatory or inhibitory synaptic action.

\section{Precise Studies of Synaptic Transmission}

From the time of Sherrington the spinal cord had remained the most favorable central site for investigation of synaptic transmission. The spinal cord became of special interest when it was realized that the large afferent (Ia) fibers from muscle spindles exert a monosynaptic excitatory action on motoneurons. Under favorable conditions a weak electrical stimulation of a motor nerve could selectively excite the Ia fibers. In 1946, Lloyd studied the Ia afferent-motoneuron synapses in reflex interaction experiments and showed that the action patterns of excitatory synapses and inhibitory synapses were virtually mirror images, with a time course of a rapid rise and a slow exponential decay over about $15 \mathrm{msec}$. There was a close resemblance between these patterns and the central excitatory and inhibitory state concepts of Sherrington.

The years 1950 and 1951 saw the first intracellular recordings of synaptic actions, which were made possible by the advent of the cathode follower amplifier. This device was used by Fatt and Katz (1951) to study neuromuscular transmission. The muscle fiber endplate potential was thus recorded directly, rather than indirectly by the extracellularly recorded current it generated. A new world of synaptic transmission was opened upthe endplate potential (EPP), with its pharmacologically graded amplitude, its normally constant time course lengthened by anticholinesterases, its decremental spread along the muscle fiber, and its generation of muscle impulses. All this was as predicted by theory and extracellular recordings; but not the biological noise, as it was at first called, that was generated in the endplate region in the resting state, apparently by spontaneous release of ACh from the nerve terminals. The explanation of the "quantal" nature of these miniature EPPs (del Castillo and Katz, 1954) came with the discovery of presynaptic vesicles by electron microscopy (Robertson, 1956).

The first intracellular recordings of synaptic potentials in motoneurons were made in 1951 (Brock et al., 1952). An essential requirement for their interpretation was that the potentials recorded were attributable to impulses in Ia afferent fibers that acted monosynaptically on the motoneurons. Impulses in higher-threshold Ib and II afferent fibers with diverse polysynaptic actions would have confused the experiment. Excitatory synapses produced the expected depolarization with a fast onset and a slow decline, the excitatory postsynaptic potential (EPSP; Fig. 3E), much like the neuromuscular EPP. The unexpected finding was that inhibitory synapses produced a hyperpolarization, the inhibitory postsynaptic potential (IPSP; Fig. $3 A-C$ ), which was almost a mirror image of the EPSP (Fig. $3 D, E$ ). These 2 types of mirror-symmetric synaptic potentials (Fig. 3) were precisely what was needed to explain the phenomena that had been observed in the earlier studies in reflexes and their inhibition, the c.e.s. and c.i.s. of Sherrington's terminology (1925) and the later studies of Lloyd (1946).

It was immediately recognized that both EPSPs and IPSPs were the result of chemical synaptic transmission. Electrical synaptic transmission now fell into disfavor, though it eventually made a comeback in other contexts. Now, 3 basic problems emerged: (1) the neuronal pathways of the Ia impulses in 
A Simple

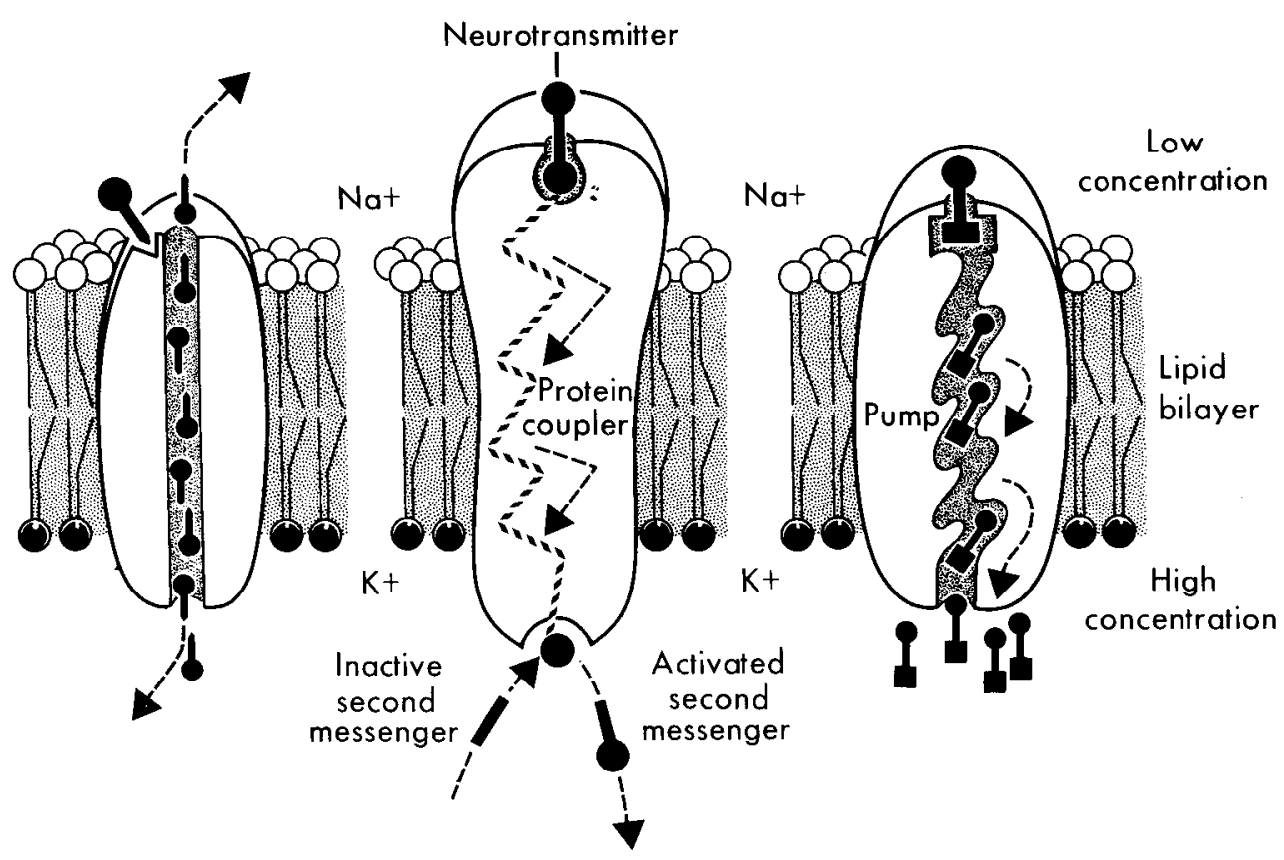

C Active

transport
Figure 2. Organization of the outer cell membrane. The basic structure is a bimolecular leaflet of phospholipid molecules with their hydrophilic parts at the surface. Structural proteins (not shown) are attached to both outside (top) and inside (bottom) surfaces to provide stability. This figure shows diagrammatic depictions of three types of receptors: $A$, An ionotropic receptor which opens ion channels on activation by a neurotransmitter. $B$, A metabotropic receptor which, on activation by a neurotransmitter, triggers a transmembrane activation of a second messenger. $C, \Lambda$ high-affinity neurotransmitter uptake system which "pumps" extracellular neurotransmitter at a low concentration into a nerve ending at a high concentration (McGeer et al., 1987). the spinal cord that would provide for excitation of the synergist motoneurons and inhibition of the antagonist motoneurons; (2) the identification of the excitatory and inhibitory transmitter substances; and (3) the mode of action of these substances to generate EPSPs and IPSPs.

\section{Inhibitory Interneurons}

Until 1954 it was thought that, as was envisaged by Sherrington (Fig. 1), an axon of a brain neuron could form directly both excitatory and inhibitory synapses. These opposite synaptic functions were attributed to the same transmitter substance acting on postsynaptic receptor sites with different properties. For example, it was observed that in the case of the Ia afferent fiber from a muscle spindle, one branch was excitatory to homonymous motoneurons and another branch inhibitory to antagonist motoneurons (Fig. 3). However, the latency of the IPSPs was longer by about $0.8 \mathrm{msec}$ than that of the EPSPs. Paul Fatt recognized that this additional delay was just enough for the
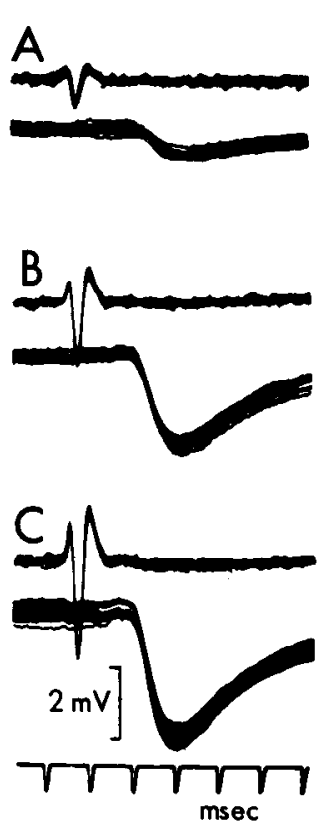
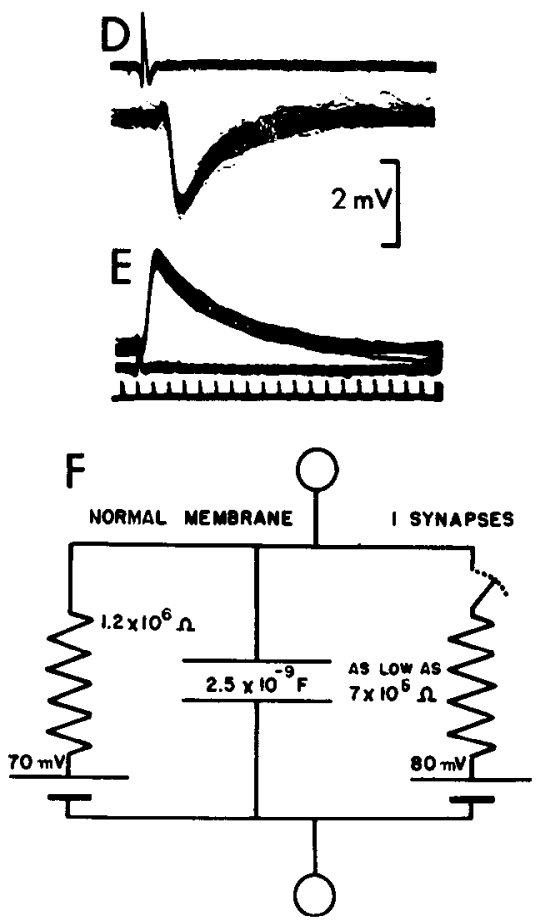

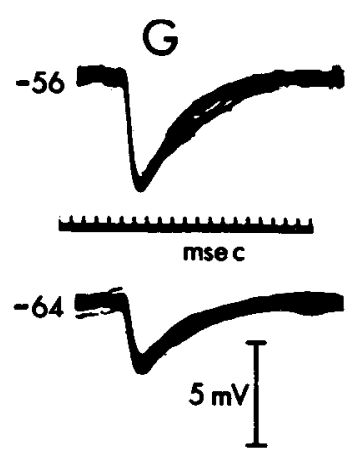

$-74$

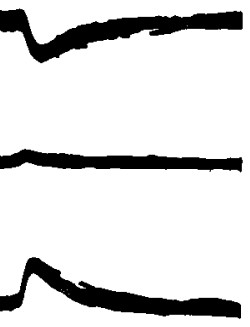

Figure 3. Postsynaptic potentials evoked in a motoneuron by Ia afferent volleys. $A-C$, IPSPs (bottom traces) evoked by graded strengths of inputs (top traces). D-E, IPSP and EPSP on same time scale $F$, Formal electrical diagram of the cell membrane, showing normal membrane to left and I synapses to the right (McGeer et al., 1987). $G$, Effect of membrane potential $(\mathrm{mV}$ to left) on EPSP amplitude. 
Figure 4. The neural pathways from and to the extensor $(E)$ and flexor $(F)$ muscles of the knee joint. The small insets show the details of the origin of the Ia afferent fibers from the annulospiral endings $(A S)$ of muscle spindles. Thence, the afferents course via the dorsal roots to enter the spinal cord and form excitatory synapses on motoneurons $(E, F, t o p)$ that innervate the muscle of origin and on interneurons $(I N)$ that inhibit synaptically the motoneurons of the antagonistic muscle. The interruptions in the nerves beyond the electrodes $(S E, S F)$ indicate a discontinuity in the diagram.
Figure 5. A, Renshaw cell excited by axon collaterals of motoneurons to give an intense repetitive discharge. $B$, Activity in the Renshaw cell exerts powerful inhibitory action on the motoneuron, a negative feedback. The IPSPs in $C$ and $D$ show the rhythmic discharge of the Renshaw cell and $E$ and $F$ give the latency of the inhibition between the 2 arrows, $F$ being an extracellular recording (Eccles et al., 1954).
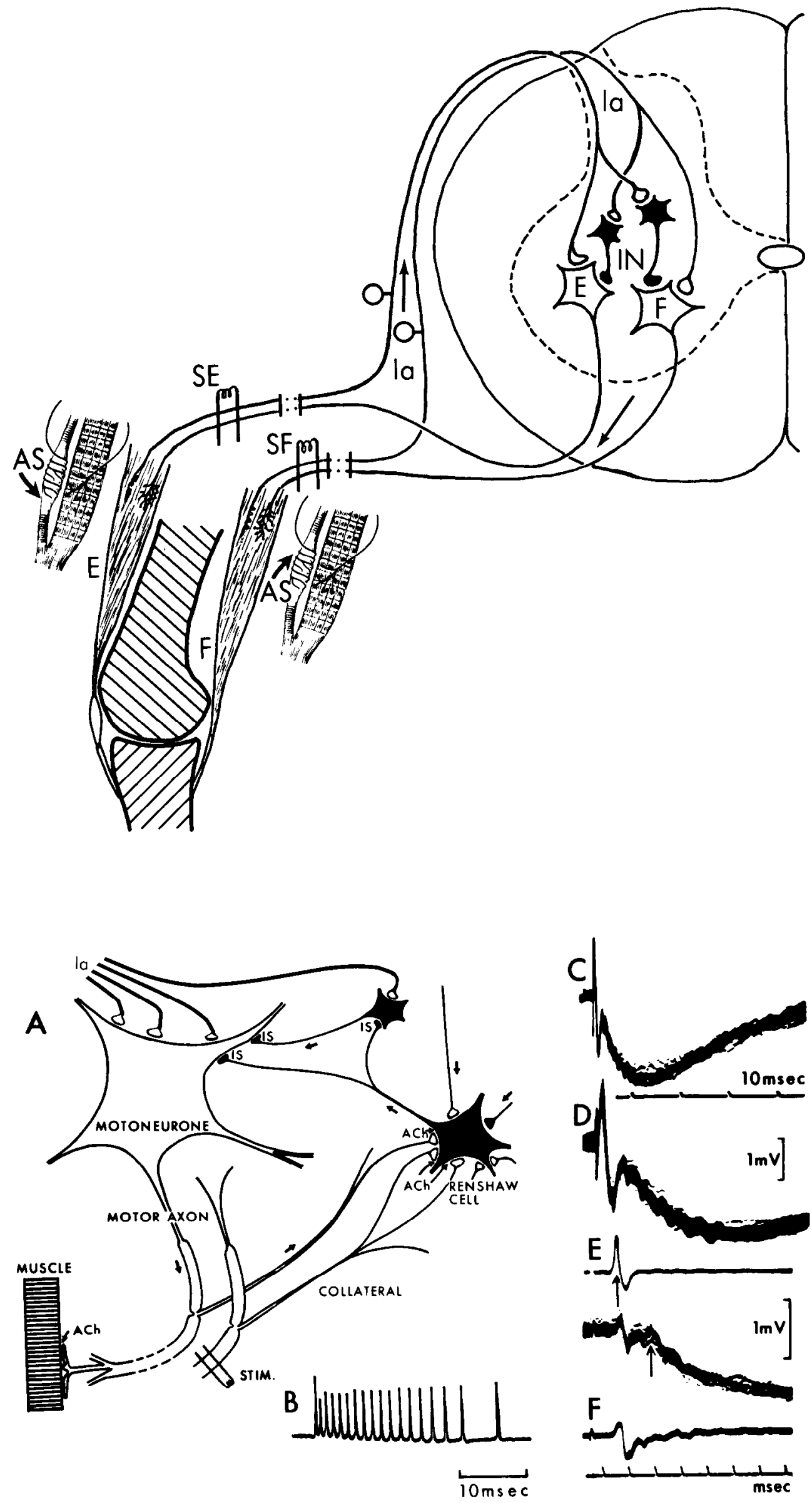


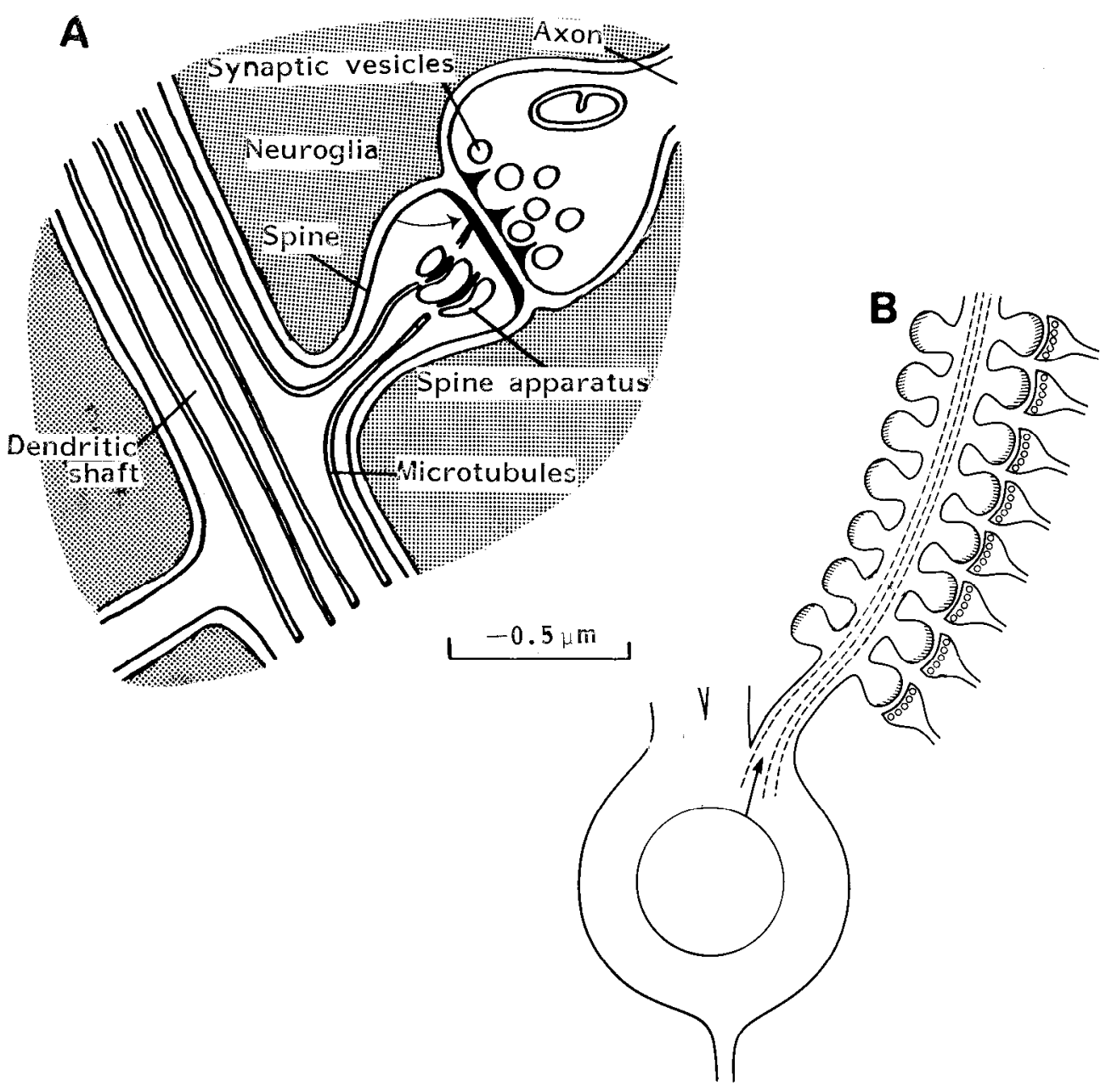

Figure 6. A, Spine synapse of a dendrite of a hippocampal pyramidal cell. From the presynaptic membrane there are dense projections up to and between the synaptic vesicles (Gray, 1982). B, A dendrite of a dentate granule cell drawn in outline with synaptic spines on both sides. Microtubules are drawn in the dendrite as interrupted lines. interpolation of an interneuron on the inhibitory pathway. Such presumptive interneurons were identified in the intermediate nucleus of the spinal cord (Eccles et al., 1956), but the principal ones were missed in the original investigation. So the puzzle of how one branch of an axon would provide excitation and another inhibition was solved by the interpolation of an interneuron in the inhibitory pathway, as is illustrated in Figure 4.

At about the same time (Eccles et al., 1954), it was shown that the interneurons first recognized by Renshaw received direct excitatory synaptic inputs from axon collaterals of motoneurons and provided direct inhibitory synaptic inputs to these same motoneurons (Fig. 5). So here was another example of an inhibitory interneuron. Inhibitory interneurons have also been identified in other inhibitory pathways in the spinal cord, and many similar discoveries were made at higher levels-as with, for example, the basket cells of the hippocampus and of the cerebellum. In the light of these initial discoveries it was proposed that the neurons of the central nervous system were either excitatory or inhibitory, and that there were no ambivalent neurons in the central nervous system. This proposal came under heavy attack, but the additional findings cited above and a wealth of new discoveries have apparently silenced the opposition! It is all but forgotten, and young neuroscientists do not realize that, until about 1960, this was a heavily disputed concept.

Figure 5 provides an illustration of Dale's Principle, that a given type of nerve cell operates at all of its synapses by the same chemical transmission mechanism (Eccles, 1957, p. 212; for a more extensive description, see Eccles, 1986). In the example of Figure 5, $\mathrm{ACh}$ is the transmitter for motoneuronal excitation of such different entities as muscle fibers and Renshaw cells in the spinal cord.

\section{Electron Microscopy}

One of the most important discoveries about the nature of synapses came in the 1950s through the use of electron microscopy (Palade and Palay, 1954; Palay and Palade, 1955). Light microscopy had given essential information about synapses by visualization of the enlarged presynaptic terminal or bouton in close contact with the postsynaptic membrane of the neuronal soma and dendrites. Electron microscopy gave fundamental information on the mechanism of synaptic transmission (Fig. 6). First, there is a narrow synaptic cleft with a gap of only $200 \AA$ between the pre- and postsynaptic cell membranes. Second, there are the synaptic vesicles about $400 \AA$ in diameter. They are scattered in the bouton and characteristically arranged along the presynaptic cell membrane to form the presynaptic vesicular grid (PVG; Fig. 7A), apparently in readiness to release their contained transmitter molecules by exocytosis into the synaptic cleft (Fig. 7B). This is the essential mechanism of chemical transmission. Depolarization of the terminal by the presynaptic 


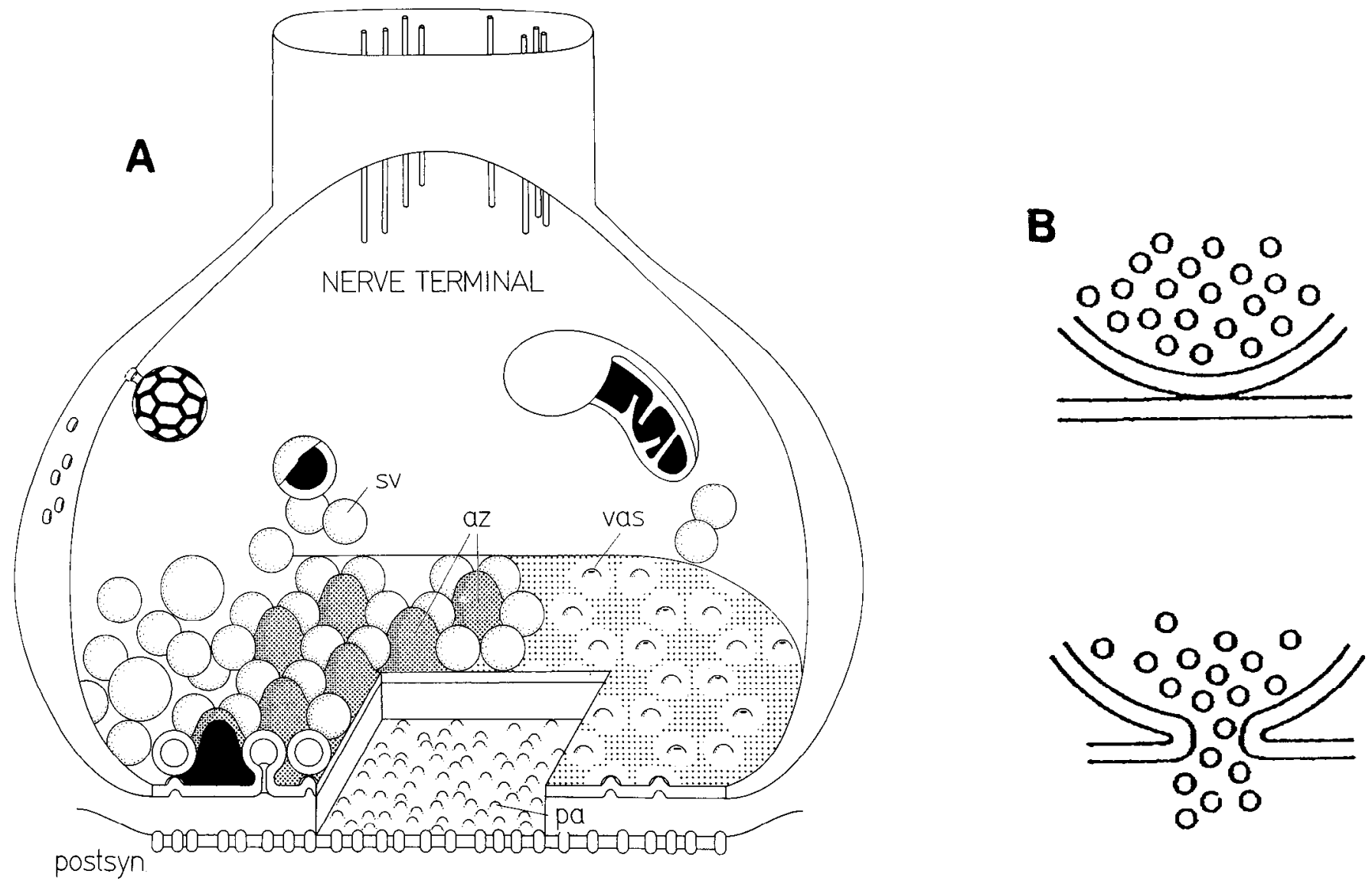

Figure 7. A, Schema of the mammalian central synapse. The active zone $(A Z)$ is formed by presynaptic dense projections. $S V$, Synaptic vesicles; $P A$. particle aggregation on postsynaptic membrane (postsyn.). Note synaptic vesicles in hexagonal array on the left and vesicle attachment sites $(V A S)$ on the right (Akert et al., 1975). B, Stages of exocytosis with release of transmitter into the synaptic cleft.

Figure 8. A, Averaged recordings of EPSPs in 6 motoneurons produced by impulses in the same la fiber terminating on them. $B$, Summary diagram of the location of Ia synapses from a single medial gastrocnemius $(M g)$ Ia fiber onto a medial gastrocnemius motoneuron at 5 sites on 3 different dendrites. $C$, Four EPSPs evoked by a single Ia fiber impulse, selected from a set of 800 responses. $D$. Average of all the 800 responses. $E-H$, Components of the EPSP derived from fluctuation analysis. The probabilities of the occurrence of these components are indicated to the right of each. I, Reconstructed EPSP obtained by adding the weighted values of E-H: $0.29(E)+0.5(F)+0.16(G)+$ $0.05(H)$ (from Jack et al., 1981).
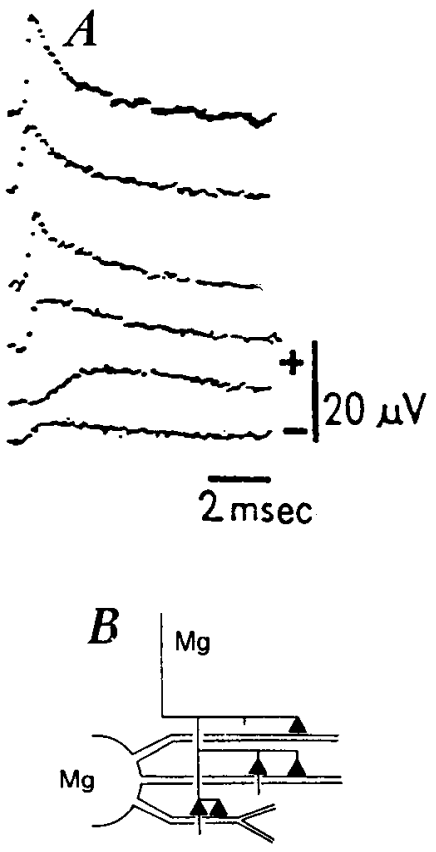

C

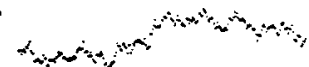

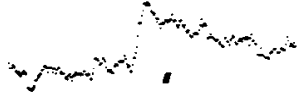

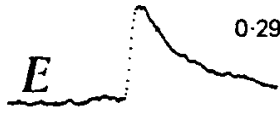

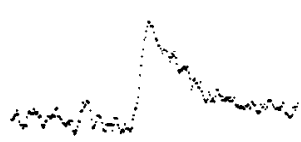

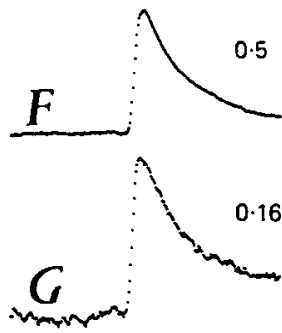

D

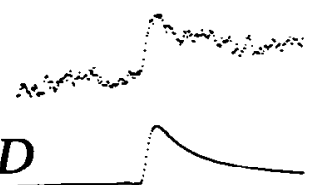

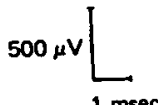
$1 \mathrm{msec}$

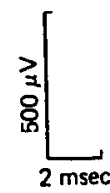

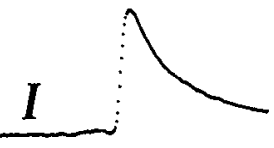




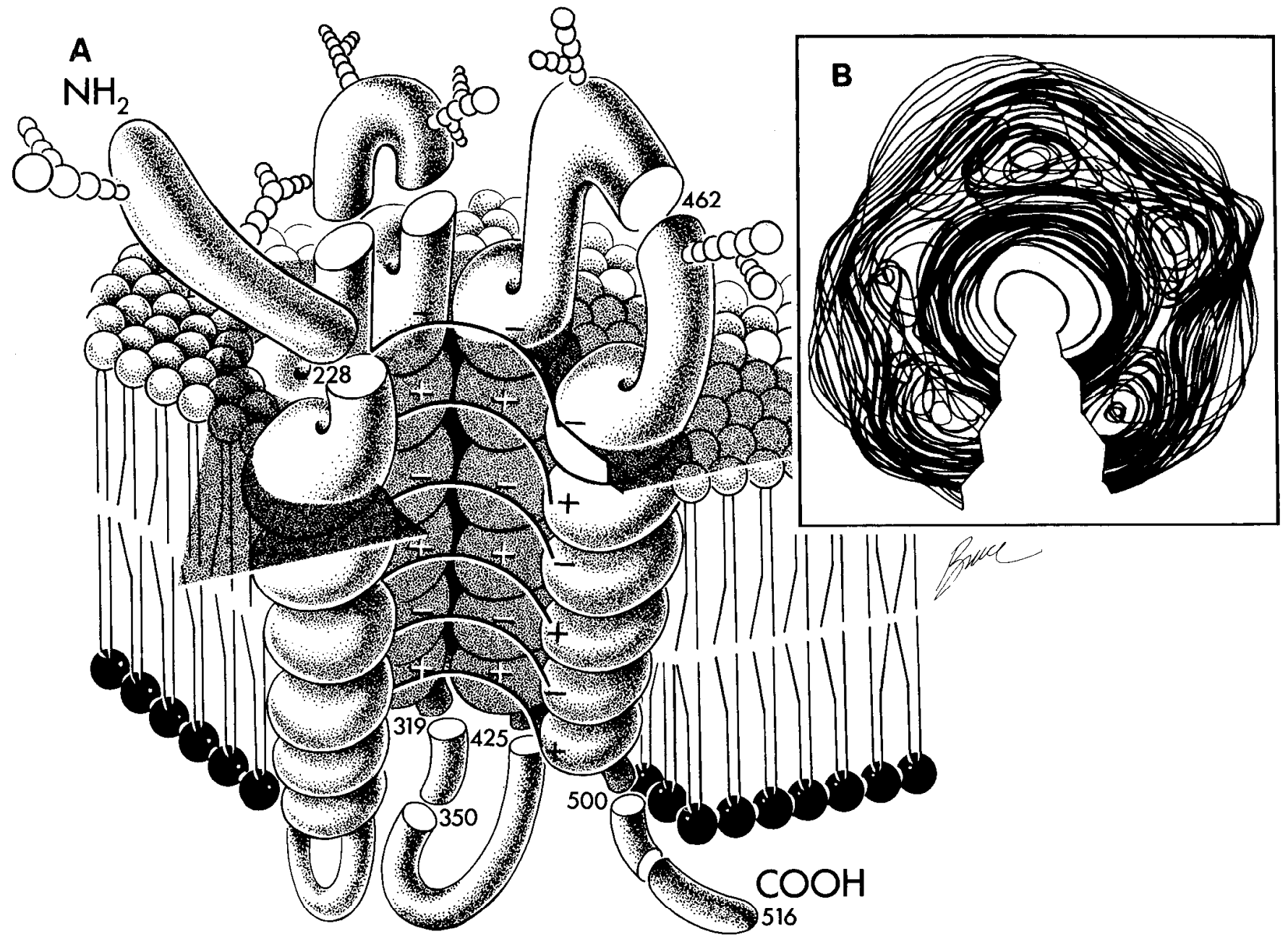

Figure 9. Model of the nicotinic receptor. $A$, The bimolecular leaflet has been opened to expose the glycoprotein that comprises the nicotinic receptor. The $\mathrm{NH}_{2}$ terminus of the protein is located outside the membrane. The protein has 5 stretches of amino acids, wound in an $\alpha$-helix which traverses the membrane and presumably corresponds to short stretches of the $2 \alpha, 1 \beta, 1 \tau$, and $1 \delta$ subunits of the receptor. Cuts indicate where stretches of the protein are not shown. The locations of identified sequences in the protein that are inside or outside the membrane are indicated by the amino acid number in the polypeptide chain, which is 516 amino acids long. Simulated charges along the channels are indicated on the basis of presumed amino acids (adapted from Young et al., 1985). B. Three-dimensional contour map of a receptor molecule, based on electron microscope images, as seen from the synapse looking down the channel (adapted from Brisson and Unwin, 1985).

impulse causes an influx of $\mathrm{Ca}^{2+}$ ions into the bouton. The combination of $\mathrm{Ca}^{2+}$ with calmodulin then mediates the process of exocytosis (Fig. 7B), which releases transmitter into the synaptic cleft.

It was a great discovery by Gray (1959) that the numerous spines on the dendrites of neurons in the cerebral cortex are synapses (Fig. 6A,B), there being many thousands of such excitatory spine synapses on the dendrites of a pyramidal cell. Figure $7 A$ is an idealized diagram by Akert et al. (1975) of a synapse, there being 30-50 vesicles arranged along the presynaptic vesicular grid.

By means of highly refined techniques, Redman and associates (Fig. 8; Jack et al., 1981) have shown that a presynaptic impulse never causes more than one exocytosis per terminal, and even that rather rarely. Thus the amplitudes of recorded EPSPs (Fig. $8 C$ ), fluctuate widely upwards from zero; but when large numbers are summed, the recorded EPSP is steady (Fig. 8D), resembling that shown in Figure $3 E$. The probability of exocytosis per terminal per impulse is much the same for the 3 sites so far studied: motoneurons, hippocampal pyramidal cells, and the inhibitory synapses on the Mauthner cells of goldfish (Korn and Faber, 1986). It would be of great interest if these techniques could be applied to pyramidal cells of the cerebral cortex.

\section{Chemical Synaptic Transmission}

The outer membrane of neurons has the basic structure of a biomolecular leaflet about $70 \AA$ wide and is composed of phospholipid molecules whose hydrophilic polar groups point outwards and inwards, as shown in Figures 2 and $9 \mathrm{~A}$. This lipid bilayer presents an impermeable barrier to the flow of watersoluble molecules and ions. Up to $6 \%$ of the lipids are made up of glycolipids that contain one or more sialic acid residues, one type of which was identified by Edelman (1983) as a cell adhesion molecule (CAM). The protein molecules that extend across the membrane, as indicated in Figure 2, are of special interest. The principal 3 types are (1) ionic diffusion channels, (2) metabolic activation channels, and (3) active transport channels.

An intensive study of chemical transmission across synapses by a diversity of powerful techniques has revealed that the transmission process is much more complicated than was envisaged 
Table 1. Neurotransmitters

\begin{tabular}{lll}
$\begin{array}{l}\text { Type I: } \\
\text { amino acids }\end{array}$ & $\begin{array}{l}\text { Type II: } \\
\text { amines }\end{array}$ & $\begin{array}{l}\text { Type III: } \\
\text { peptides }\end{array}$ \\
\hline Glutamate & Acetylcholine & Cholecystokinin \\
Aspartate & Dopamine & Substance P \\
GABA & Noradrenaline & Vasoactive intestinal polypeptide \\
Glycine & Serotonin & Somatostatin \\
& Histamine & Luteinizing-hormone-releasing \\
& & hormone \\
& & Dynorphin \\
& & Vasopressin \\
& & Neurotensin \\
& & Adrenocorticotropic hormone \\
& & Thyrotropin-releasing hormone
\end{tabular}

originally (McGeer et al., 1987, Chapter 5). A neurotransmitter can be defined as a molecule that is concentrated in synaptic vesicles of a bouton and released when the bouton is invaded by an impulse. Three criteria have to be satisfied in the identification of a substance as a transmitter: (1) localization in specific neurons, (2) release from presynaptic terminals in response to a presynaptic impulse in a calcium-dependent manner, and (3) physiological action at postsynaptic receptor sites. Almost all known or proposed transmitters belong to one of 3 chemical types: amino acids, amines, or peptides (Table 1). The number of different transmitters has grown enormously from the first transmitters that were discovered, the amines acetylcholine and adrenaline (Type II), and those transmitters discovered next, the amino acids GABA and glycine, glutamine, and aspartate (Type I), to the long list of peptide transmitters (Type III).

Transmitters can act on the postsynaptic receptors by 2 quite different mechanisms, as illustrated in Figure $2 A, B$ (McGeer et al., 1987, Chapter 5). In ionotropic action (Fig. 2A), the transmitter opens ionic channels across the membrane. The ions diffuse through the opened channels down their electrochemical gradients, producing a change in membrane potential, an EPSP or an IPSP, as illustrated in Figure 3 . In the metabotropic action (Fig. $2 B$ ) the transmitter brings about postsynaptic metabolic changes. Instead of ionic flow, sequences of enzymatically driven reactions involving second-messenger systems change the electrophysiological state of the cell. Metabolic actions are much slower than ionotropic action, with time courses measuring hundreds of milliseconds. Under its muscarinic action $\mathrm{ACh}$ is a metabotropic transmitter as, for example, in the slow vagal inhibition of the heart. In contrast, under its nicotinic action, $\mathrm{ACh}$ is an ionotropic transmitter with the fast initial action at the neuromuscular junction and the sympathetic ganglion synapses. However, in the sympathetic ganglion, $\mathrm{ACh}$ also has a delayed metabotropic action. Amines (Type II) and peptides (Type III) can be metabotropic transmitters.

The coexistence of different transmitters at the same synapse is a rapidly expanding field of research (Hökfelt et al.,1986). A classical transmitter (Types I or II of Table 1) may coexist with one or more peptides, or there may be more than one classical transmitter, or there may be a classical transmitter (Types I and II), a peptide (Type III), and ATP (adenosine triphosphate). Hökfelt et al. (1986) fully discuss the physiological significance of cotransmitters.

\section{lonic Channels}

The ionic channel schematically shown in Figure $2 A$ has been the subject of a scientific breakthrough that happened with unprecedented speed as several research teams produced a highly sophisticated, generally accepted solution (Noda et al., 1984).

The ionic channel for the acetylcholine receptor (AChR) of a torpedo electroplaque is composed of a single protein whose sequence of 516 amino acids has been determined. It includes along its length 5 subunits, each composed of just over 20 similar sequences, 2 being identical $(\alpha)$ and 3 others $(\beta, \tau, \delta)$ being different. In the model presented in Figure $9 \mathrm{~A}$ (Young et al., 1985; McGeer et al., 1987) these subunits are shown crossing the membrane as short $\alpha$-helices, which group together to form a channel traversing the membrane. As shown in Figure $9 \mathrm{~A}$, there are considerable lengths of the AChR molecule outside of the membrane, 228 residues before the first crossing, and also many between the crossings, so that the protein forms bulges larger than that drawn in Figure $2 A$. The open channel of Figure $9 B$ is about $7 \AA$ in diameter. To be closed to ion transport, the channel diameter only needs to be a little smaller. The channel probably opens when the ligand, $\mathrm{ACh}$, attaches to double cysteines in the initial outer segment of 228 residues and causes a conformational change in the protein.

This brief outline serves to indicate the immense challenge in identifying the structure of channels across the membrane and their control by different transmitters. The AChRs of muscle and brain are closely similar to that of Figure 9 (Stevens, 1985). Proteins forming the inhibitory ionic channels of the brain activated by GABA and glycine have been partly sequenced and consist of somewhat similar $\alpha$-helices.

The present intensity of investigation ensures that the protein sequences of the ionic channels operating for the principal transmitters will soon be known.

\section{The Operation of Ionic Channels}

The ultimate refinement in the study of AChRs was achieved by employing a glass micropipette, with a tip about $1 \mu \mathrm{m}$ in diameter, to record selectively from a very small patch of membrane to which the pipette had been attached. This is the patchclamp technique pioneered by Neher and Sakmann (1976). In a further refinement, Neher found in 1979 that by gentle suction the clean, polished tip of the micropipette could be made to seal very tightly to the clean surface membrane to which it was applied. This is called the "giga-seal" technique because the resistance of the seal is many giga-ohms, even above $10 \times 10^{9}$ $\Omega$ (Corey, 1983). Thus the electrophysiological responses of a very small area of the membrane, a few square micrometers, are being selectively recorded by the micropipette.

When the physiological saline in the micropipette contains a low concentration of ACh, the activation of the AChR sites on the external surface of the patch opens ion channels across the membrane. As shown in Figure 10A, opening of the channels by a $100-n M$ solution of $\mathrm{ACh}$ results in inward current pulses that are of widely different duration, but of the same amplitude, there being a very small variance about the mean of $2.7 \mathrm{pA}$. When a long series of channel openings is analyzed, it can be seen that most of them last no longer than $1 \mathrm{msec}$. These brief openings are interpreted as being affected by the interaction of a single molecule of $\mathrm{ACh}$ with the channel receptor, while the longer openings are being affected by the attachment of 2 molecules of ACh to the receptor of the channel. It can also be seen 
Acetylcholine
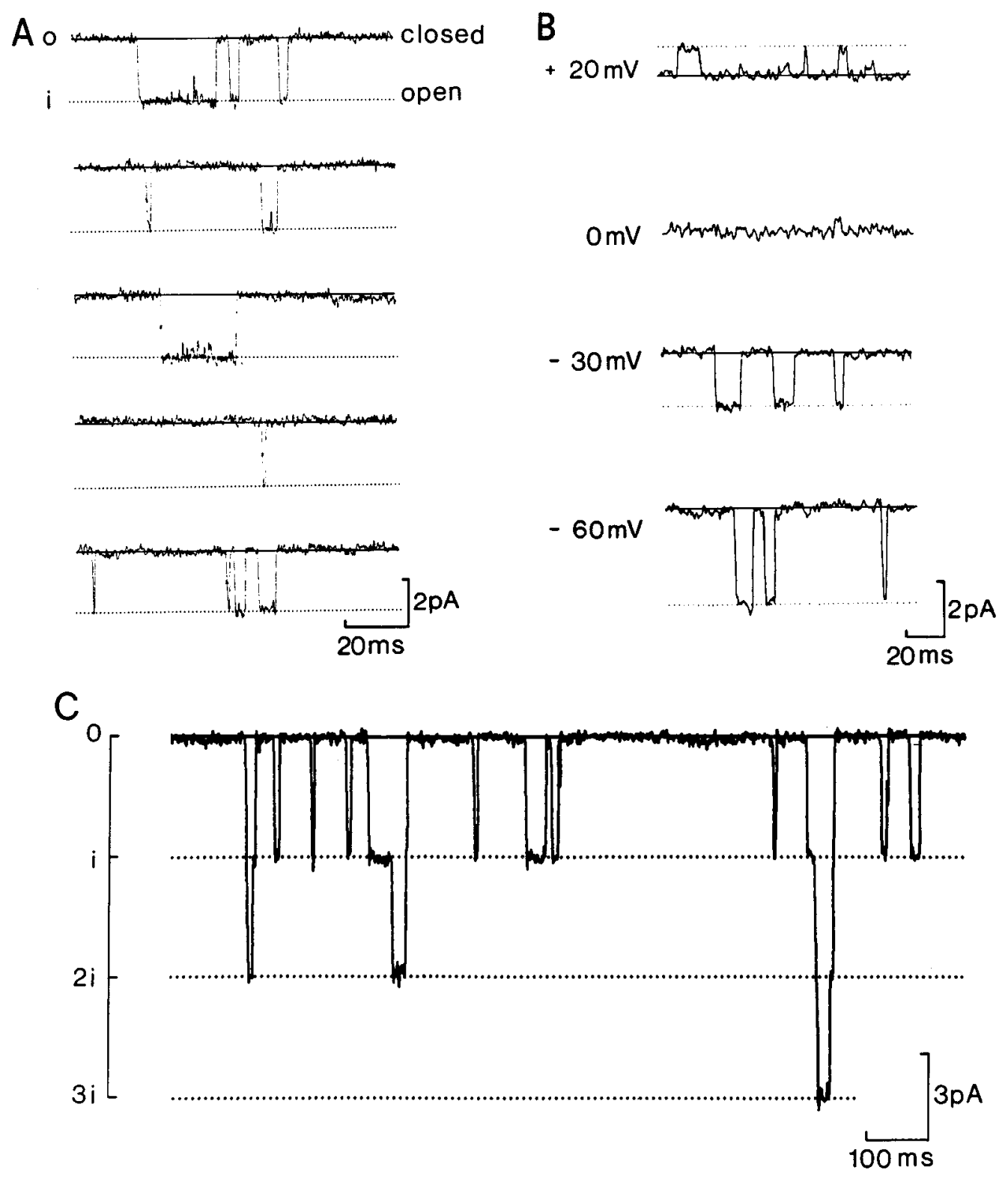

Figure 10. A, Single-channel currents recorded in the presence of $100 \mathrm{nM} \mathrm{ACh}$ from a frog muscle fiber at the resting membrane potential of $-92 \mathrm{mV}$. The temperature was $10^{\circ} \mathrm{C}$. Downward deflection indicates inward current. The distribution of current pulse amplitudes has a peak at $2.7 \mathrm{pA}$. $B$, Voltage dependence of single-channel currents activated by $2 \mu \mathrm{M}$ ACh in rat embryonic muscle. The temperature was $23^{\circ} \mathrm{C}$ Downward deflection indicates inward current; upward deflection, outward current. $C$, Single-channel currents recorded in the presence of $100 \mathrm{~nm} \mathrm{ACh}$ from a frog muscle fiber at $-130 \mathrm{mV}$ membrane potential. The temperature was $10^{\circ} \mathrm{C}$. Currents of 3 individual channels superimpose to form regularly spaced amplitude levels of $-3.9 \mathrm{pA}$ (from Colquhoun and Sakmann, 1981).

in Figure $10 \mathrm{~A}$ that there are brief partial reductions of the current (Colquhoun and Sakmann, 1981).

The current flowing through the channel is due to ions diffusing down the electrochemical gradient across the membrane. In Figure 10B, the transmembrane potential is varied from +20 to $-60 \mathrm{mV}$ by an applied current. The amplitudes of the current pulses are seen to vary according to their expected linear distance on the transmembrane potential. When therc are several channels across the patch that is being recorded, the expected summation of current occurs, as illustrated in Figure $10 C$, for the current pulses of 1,2 , and 3 channels, each of amplitude 3.9 pA.

In brain neurons, receptors that open excitatory sodium channels appear mostly to be activated by glutamate/aspartate (GluAsp) transmitters. GluAsp are mentioned together because so far it has been extremely difficult to distinguish between glutamate and aspartate pathways and their receptors. A minor fraction of excitatory ionic channels may also be activated by ACh through a nicotinic type of receptor, but well over $95 \%$ of cholinergic receptors are of the metabotropic muscarinic variety.

The situation is complicated because there are 3 types of receptors for glutamate, as defined by their affinities for analogs of glutamate: quisqualate (QQ), $N$-methyl-D-aspartate (NMDA), and kainate. Physiologically only the QQ and NMDA receptors need be considered at present. In the hippocampus, glutamate acts on the QQ receptors to open channels for monovalent cations, particularly $\mathrm{Na}^{+}$(Gustafsson and Wigström, 1987). Under resting conditions $\mathrm{Mg}^{2+}$ blocks the NMDA receptors. When these ions are removed by a strong depolarization, glutamate acts to open ion channels that pass $\mathrm{Ca}^{2+}$ ions as well as monovalent cations (Gustafsson and Wigström, 1987). The NMDA receptors are uniquely distinguished by the blockage by 2-amino5-phosphonovaleric acid (APV), with the consequence that syn- 


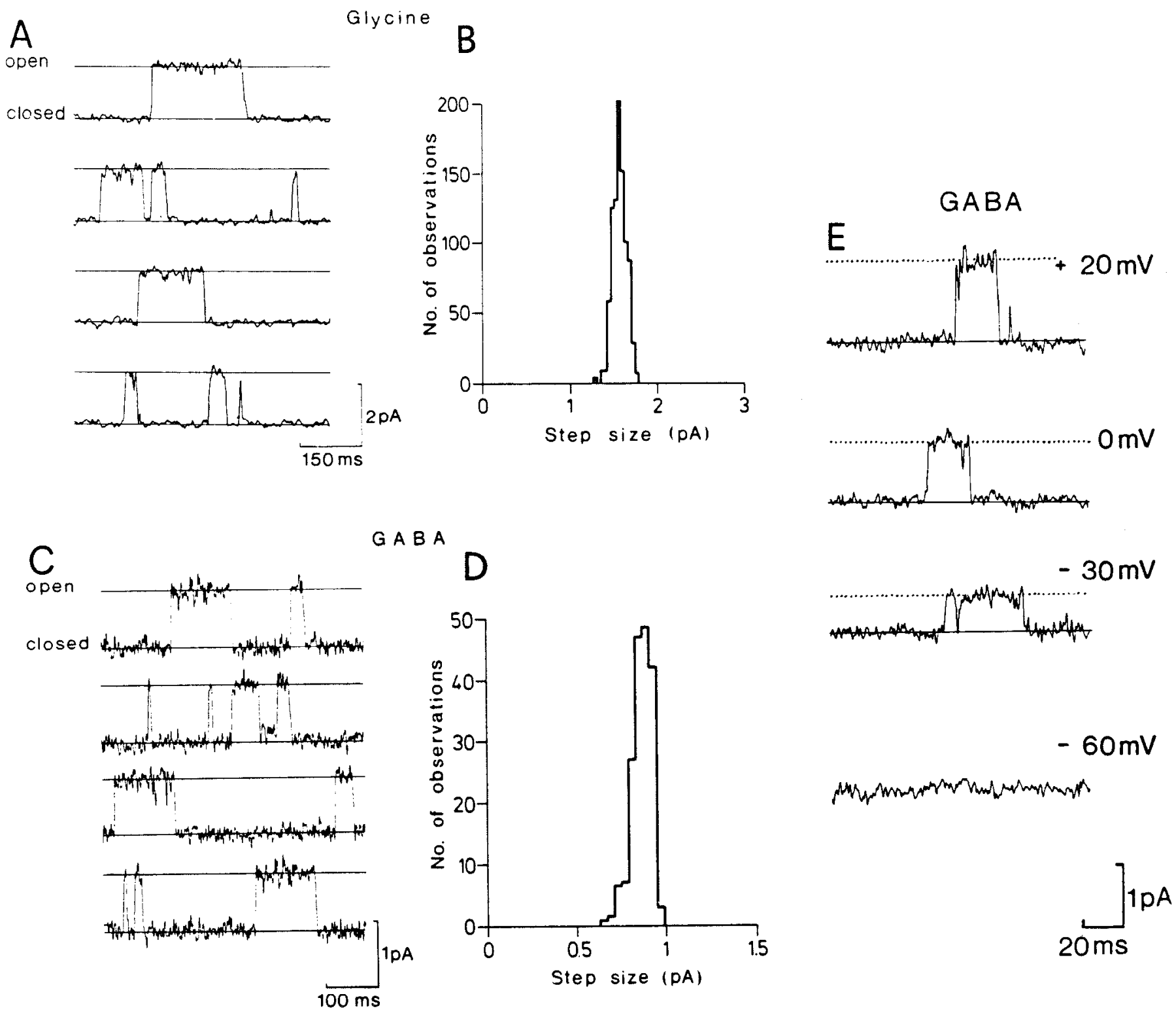

Figure 11. $A-D$, Single-channel outward currents induced by $10 \mu \mathrm{M}$ glycine $(A)$ and GABA $(C)$ in mouse spinal neurons at $0 \mathrm{mV}$ membrane potential. The temperature was $23^{\circ} \mathrm{C}$. The step-size distribution for glycine- and GABA-activated currents yield mean amplitudes of $1.4 \mathrm{pA}(B)$ and $0.8 \mathrm{pA}(D)$, respectively. $A-D$, from Sakmann et al. (1983). $E$, Voltage dependence of single-channel currents activated by $5 \mu \mathrm{M}$ GABA in a rat hippocampal neuron. The temperature was $23^{\circ} \mathrm{C}$. Downward deflection indicates inward current; upper deflection, outward current (from $\mathrm{B}$. Sakmann, personal communication, 1984).

aptic activation by glutamate fails to cause the entry of $\mathrm{Ca}^{2+}$ ions even under conditions of strong depolarization.

The GABA binding sites for central inhibitory action have a spccial fcaturc, namcly that the benzodiazcpinc recognition sitc is close to the GABA recognition site. When benzodiazepines are attached, they increase the affinity for GABA, thus enhancing the GABA inhibitory action. This enhancement is of great clinical value because of its safe tranquilizer action. By contrast, the picrotoxin recognition site acts by diminishing the $\mathrm{Cl}^{-}$conductance of the channel opened by GABA, thereby reducing the GABA inhibitory action.

The patch-clamp technique (cf. Fig. 11) has now been applied to the ion channels of inhibitory synapses (Fig. $3 F$ ) on neurons of the mammalian CNS. The surfaces of the nerve cells become accessible to micropipette application in cultures of either spinal cord (Hammil et al., 1983; Sakmann et al., 1983) or hippocampus (Bormann et al., 1983).

The 2 inhibitory neurotransmitters glycine and GABA open ionic channels with different properties, as shown in Figure 11, $A$ and $B$. Because the membrane potential was depolarized to $0 \mathrm{mV}$, far from the chloride equilibrium potential, the ionic currents induced by glycine and GABA flowed outward. They displayed the same variability of duration as did the ACh currents shown in Figure 10. The currents generated by glycine application were usually much larger than the GABA-generated currents, their amplitudes being 1.4 and $0.8 \mathrm{pA}$, respectively.

When the membrane potential was varied, the amplitudes of the ionic currents generated by application of $5 \mu \mathrm{M}$ GABA were linearly related to the membrane potential, with zero amplitude at the resting membrane potential of $-60 \mathrm{mV}$ (Fig. $11 E$ ), the 
equilibrium potential for chloride ions. This effect was observed with intracellular recording (cf. Fig. 3G). The patch-clamp technique lends itself to a thorough investigation of the anions that can tranverse the channels opened by the inhibitory transmitter. This is a problem originally studied in vivo and summarized by Eccles $(1957,1964)$. It was found that intracellular injection of small hydrated anions $\left(\mathrm{Cl}^{-}, \mathrm{Br}^{-}, \mathrm{I}^{-}, \mathrm{NO}_{2}^{-}, \mathrm{NO}_{3}^{-}, \mathrm{N}_{3}^{-}, \mathrm{ClO}_{4}^{-}\right.$, $\mathrm{SCN}^{-}, \mathrm{BF}_{4}^{-}$) caused the IPSP to change from a hyperpolarization to a depolarization. This transient effect was attributed to the ionic channels being permeable to all anions below a critical size.

Hammil et al. (1983) found that the inhibitory channels opened by glycine and GABA are identical. The channels are also permeable to other halide ions (cf. Eccles, 1957, 1964). The permeability ratios for the series $\mathrm{Br}^{-}, \mathrm{I}^{-}, \mathrm{Cl}^{-}$, and $\mathrm{F}^{-}$were $1.8: 1.5$ : 1.0:0.4 for glycine-receptor channels and 1.7:1.4:1.0:0.4 for GABA-receptor channels. The low $\mathrm{F}^{-}$permeability was not observed in vivo, but this failure may be attributable to the enzyme poisoning produced by intracellular injection of $\mathrm{F}^{-}$ions. It was confirmed that the inhibitory channels are not permeable to the large acetate or sulfate ions, in concordance with the list of 21 large anions found to be impermeable in vivo (Eccles, 1964).

Because of the similarity of the ionic permeabilities, it is suggested by Hammil et al. (1983) that the 2 inhibitory neurotransmitters may actually operate the same ion channels from their respective receptor sites. The distinction of the receptor sites is, of course, demonstrated by the sharp differentiation in blocking agents-strychnine for glycine receptors and bicuculline and picrotoxin for GABA receptors.

\section{Long-Term Potentiation or Depression as Models for Memory}

Bliss and Lømo (1973) showed that tetanic stimulation of hippocampal synapses resulted in an increased amplitude of the EPSP that had an extremely long duration-lasting even for weeks. This long-term potentiation (LTP), as it was called, was put forward as a model for cognitive memory, and consequently has been intensely investigated. Gustafsson and Wigström (1987) demonstrated that LTP was induced by a brief tetanic stimulation of excitatory synapses on a neuron, even when remote from those being tested. Even neuronal depolarization by an applied current pulse was sufficient for inducing LTP of a test synaptic input.

The explanation of an immense array of experimental findings came when it was recognized (Watkins, 1984) that there were 2 kinds of glutamate receptors (see the section on "The Operation of Ionic Channels" above), those normally acting to give an EPSP and that are identified as QQ $\alpha$-receptors, and those specially related to NMDA. The NMDA receptors are normally blocked by $\mathrm{Mg}^{2+}$ ions (Collingridge, 1985). Only when there was a large depolarization for some milliseconds were the $\mathrm{Mg}^{2+}$ ions driven off and the NMDA receptors freed to be glutamate receptors that are specially related to the opening of $\mathrm{Ca}^{2+}$ channels. The consequent influx of $\mathrm{Ca}^{2+}$ ions into the dendritic spine (cf. Fig. $6 \mathrm{~A}$ ) results in the formation of a calcium-calmodulin complex that acts as a second-messenger system. For example, this system activates the protein kinase calpain, which is presumed to cause the uncovering of the QQ glutamate receptor sites on the postsynaptic membrane, as discussed by McGeer et al. (1987, pp. 561-562).

The effect can be no more than a partial explanation of LTP. In addition, the second-messenger system appears to travel along microtubules (Fig. $6 B$ ) to the neuronal soma where it induces synthesis of macromolecules that tend to travel back to the spine of origin (Fig. $6 B$, arrow). There they cause a growth of the spine and its receptor surface, which contributes to the LTP (Eccles, 1988). There is also a presynaptic contribution to LTP by the increased output of glutamate (Dolphin et al., 1982).

This abbreviated account may serve as an introduction to more extensive treatments by Gustafsson and Wigström (1987) and by Eccles (1988). It has to be recognized that the LTP is an imperfect model for cognitive memory that, with enforcement by occasional replays, can last throughout a lifetime.

The converse synaptic learning mechanism, long-term depression (LTD), has been found only for the synaptic excitatory action of parallel fibers in Purkinje cells of the cerebellum (Ito, 1989). It is induced when there is conjunction of repetitive climbing fiber inputs with repetitive parallel fiber inputs. Its duration has not been observed beyond $3 \mathrm{hr}$ because of technical limitations. As with LTP, LTD is induced by the influx of $\mathrm{Ca}^{2+}$ into the dendrites and is canceled by the interneuronal injection of the calcium chelator EGTA. The review by Ito (1989) should be consulted for an authoritative account of this unique phenomenon, which is due to a desensitization of the quisqualatespecific glutamate receptors of the parallel fiber synapses.

One hypothesis with considerable experimental support is that $\mathrm{Ca}^{2+}$ ions desensitize glutamate receptors by a second-messenger system involving cGMP (Ito, 1989). An additional factor may be a change in the structural configuration of the dendritic spines.

Evidently, there is a great challenge in the attempt to understand this unique memory mechanism. Doubtless this memory system evolved in relation to the inhibitory action of Purkinje cells on the nuclear cell output from the cerebellum. LTD of the Purkinje cell dendrites would cause LTD of the inhibitory action of Purkinje cells on nuclear cells and, hence, an LTP of the output from the cerebellum.

\section{Trophic Interactions Between Neurons}

This is an immense field that has been dealt with at length by McGeer et al. (1987, Chapter 13) and, more recently, in comprehensive and authoritative book (Purves, 1988).

Trophic influences reach neurons via synaptic contacts with other neurons or other targets. There is conclusive evidence of retrograde transport of the nerve growth factor (NGF) to the sympathetic nervous system (Purves and Lichtman, 1985) and it has been postulated that similar neurotrophic factors act in the central nervous system. There is an intensive search for these factors. Trophic influences have been recognized as playing a role in neuronal integration matching that of the synaptic system recognized by Sherrington (1906).

It is most exciting that a brain-derived neurotrophic factor (BDNF) has now becn discovercd and subjected to complete amino acid sequencing (Leibrock et al., 1989). BDNF is structurally related to the NGFs, there being 51 amino acid sequences in common. This similarity will be of great importance in the discovery of other BDNFs. This BDNF occurs in the superior colliculus and in the spinal cord and has a trophic influence.

\section{Future Developments}

An important future development would be an improved control in cutting slices of neuronal tissues, making possible the selective stimulation of the nerve fibers projecting to a site from which recordings are taken. A remarkable technique now avail- 
able should facilitate this development, namely, the use of interference infrared beams that enable Nomarski optics to give sharply focused pictures at $100-200-\mu \mathrm{m}$ depths, where the neurons of the slices are undamaged $(\mathrm{H}$. V. Dodt, personal communication).

We need further studies of the mechanism of quantal transmitter release from single presynaptic boutons (e.g., in the neocortex) and of the factors modulating the probability of release, as has been done by Redman and associates (Jack et al., 1981). These studies would be associated with an inquiry into the manner of global operation of the preganglionic vesicular grid to limit exocytosis to an average of less than 1 vesicle per impulse per bouton.

Elucidation is needed of the molecular control of transmembrane ion channels, especially of the manner in which the attachment of a transmitter molecule to a receptor site causes a molecular transformation that opens the ion channel.

There is immense scope for future investigations of the memory mechanisms at higher levels of the brain. A good start has been made with the identification of the role of the NMDA receptor of a $\mathrm{Ca}^{2+}$ channel in this process. But the full range of the $\mathrm{Ca}^{2+}$ action in synaptic transmission requires much further study, particularly of the manner in which $\mathrm{Ca}^{2+}$-modulated second messengers act on the genome, which selectively signals back to particular synapses to produce LTP. Very little is known as yet about the neuronal factors responsible for the extremely long duration of memory traces.

The trophic influcnecs excrtcd by some ncurons on other neurons offer great opportunities for future investigations. Now that the first brain-derived neurotrophic factor has been isolated and completely sequenced, other factors are being isolated; thus we can hope for new insights into the role of such factors in the central nervous system in both health and disease.

\section{References}

Adrian ED, Bronk DW (1929) The discharge of impulses in motor nerve fibers. Part II. The frequency of discharge in reflex and voluntary contractions. J Physiol 67:119-151.

Akert K, Peper K, Sandri C (1975) Structural organization of motor endplate and central synapses. In: Cholinergic mechanisms (Waser PG, ed), pp 43-57. New York: Raven.

Bliss TVP, Lomo T (1973) Long-lasting potentiation of synaptic transmission in the dentate area of the anaesthetized rabbit following stimulation of the perforant path. J Physiol 232:331-356.

Bormann J, Sakmann B, Seifert W (1983) Isolation of GABA-activated single-channel $\mathrm{Cl}^{-}$currents in the soma membrane of rat hippocampal neurones. J Physiol 341:9P-10P.

Brisson A, Unwin PNT (1985) Quaternary structure of the acetylcholine receptor. Nature 315:474 480 .

Brock LG, Coombs JS, Eccles JC (1952) The recording of potentials from motoneurones with an intracellular electrode. J Physiol 117: $431-460$.

Brown GL, Eccles JC (1934) The action of a single vagal volley on the rhythm of the heart beat. J Physiol 82:211-241.

Collingridge GL (1985) Long-term potentiation in the hippocampus mechanisms of initiation and modulation by neurotransmitters. Trends in Pharmacol Res 6:407-411.

Colquhoun D, Sakmann B (1981) Fluctuations in the microsecond time range of the current through single acetylcholine receptor ion channels. Nature 294:464-466.

Corey DP (1983) Patch clamp: current excitement in membrane physiology. Neurosci Commentaries 1:99-110.

Creed RS, Denny-Brown D, Eccles JC, Liddell EGT, Sherrington CS (1932) Reflex activity in the spinal cord. London: Oxford UP.

Dale HH (1937) Transmission of nervous effects by acetylcholine. Harvey Lectures 32:229-245.

del Castillo J, Katz B (1954) Quantal components of the endplate potential. J Physiol 124:560-573.
Denny-Brown D (1929) On the nature of postural reflexes. Proc R Soc [Biol] 104:253-301.

Dolphin AC, Errington ML, Bliss TVP (1982) I ong-term potentiation of the perforant path in vivo is associated with increased glutamate release. Nature 297:496-498.

Eccles JC (1936) Synaptic and neuromuscular transmission. Ergeb Physiol 38:339-444.

Eccles JC (1957) The physiology of nerve cells. Baltimore: Johns Hopkins UP.

Eccles JC (1964) The physiology of synapses. Berlin: Springer-Verlag.

Eccles JC (1986) Chemical transmission and Dale's Principle. In: neuropeptides in central nervous system (Hökfelt T, Fuxe K, Björklund A, eds). Amsterdam: Elsevier.

Eccles JC (1988) Mammalian systems for storing and retrieving information. In: Cellular mechanisms of conditioning and behavioral plasticity (Woody CD, Alkon DL, MacGaugh JL, eds). New York: Plenum

Eccles JC, Katz B, Kuffler SW (1943) Effect of eserine on neuromuscular transmission. J Neurophysiol 5:211-230.

Eccles JC, Fatt P, Koketsu K (1954) Cholinergic and inhibitory synapses in a pathway from motor-axon collaterals to motoneurones. $J$ Physiol 126:524-562.

Eccles JC, Fatt P, Landgren S (1956) The central pathway for the direct inhibitory action of impulses in the large afferent nerve fibres to muscle. J Neurophysiol 19:75-98.

Edelman GM (1983) Cell adhesion molecules. Science 219:450-457.

Fatt P, Katz B (1951) An analysis of the end-plate potential recorded with an intra-cellular electrode. J Physiol 115:320-370.

Gray EG (1959) Electron microscopy of synaptic contacts on dendritic spines of the cerebral cortex. Nature 183:1592-1593.

Gray FG (1982) Rehabilitating the dendritic spine. Trends in Neurosci 5:5-6.

Gustafsson B, Wigström H (1987) Hippocampal long-lasting potentiation produced by pairing single volleys and brief conditioning tetani evoked in separate afferents. J Neurosci 6:1575-1582.

Hammil OP, Bormann J, Sakmann B (1983) Activation of multiple conductance-state chloride channels in spinal neurones by glycine and GABA. Nature 305:805-808.

Hoffmann P (1922) Untersuchungen über die eigenreflexe (Sehnenreflexe) menschlicher muskeln. Berlin: Springer-Verlag.

Hökfelt T, Holets VR, Staines W, Meister B, Melander T, Schalling M, Schultzberg M, Freedman J, Björklund H, Olson K, Lindh B, Elfin LG, Lundberg JM, Lindgren JA, Samuelsson B, Pernow B, Terenius L, Post C, Everitt B, Goldstein M (1986) Coexistence of neuronal messengers-an overview (Hökfelt T, Fuxe K, Pernow B, eds). Amsterdam: Elsevier.

Ito M (1989) Long-term depression. Annu Rev Neurosci 12:85-102.

Jack JJB, Redman SJ, Wong K (1981) The components of synaptic vesicles evoked in cat spinal motoneurones by impulses in single group Ia afferents. J Physiol 321:65-96.

Kom H, Faber DS (1986) Regulation and significance of probablistic release mechanisms at central synapses. In: New insights into synaptic function (Edelman GM, Gall WE, Cowan WM, eds). New York: Wiley.

Leibrock J, Lottspeich F, Hohn A, Hofer M, Hengerer B, Masiekowski $P$, Thoenen $H$, Barde $Y$-A (1989) Molecular cloning and expression of brain-derived neurotrophic factor. Nature 341:149-152.

Lloyd DPC (1946) Facilitation and inhibition of spinal motoneurons. J Neurophysiol 9:421-438.

Loewi O (1921) Über humorale übertragbarkeit der herznervenwirkung. Pfluegers Arch 189:239-242.

McGeer PL, Eccles JC, McGeer E (1987) The molecular ncurobiology of the mammalian brain, 2 nd edition. New York: Plenum.

Neher E, Sakmann B (1976) Single-channel currents recorded from membrane of denervated frog muscle fibers. Nature 260:779-802.

Noda M, et al. (1984) Primary structure of the Electrophorus electricus sodium channel deduced from a cDNA sequence. Nature 312:121127.

Palade GE, Palay SL (1954) Electron microscope observations of interneuronal and neuromuscular synapses. Anat Rec 118:335.

Palay SL, Palade GE (1955) The fine structure of neurons. J Biophys Biochem Cytol 1:69-88.

Purves D (1988) Body and brain: a trophic theory of neural connections. Cambridge, MA: Harvard UP.

Purves D, Lichtman JW (1985) Principles of neural development. Sunderland, MA: Sinaucr. 
Robertson JD (1956) The ultrastructure of a reptilian myoneural junction. J Biophys Biochem Cytol 2:381-394.

Sakmann B, Hammil O, Bormann J (1983) Patch-clamp measurements of elementary chloride currents activated by the putative inhibitor transmitters GABA and glycine in mammalian spinal neurons. J Neural Transm [Suppl] 18:83-95.

Sherrington CS (1906) Integrative action of the nervous system. New Haven: Yale UP.

Sherrington CS (1925) Remarks on some aspects of reflex inhibition. Proc R Soc [Biol] 97:519-545.
Stevens CF (1985) AChR structure: a new twist in the story. Trends in Neurosci $8: 1-2$.

Watkins JC (1984) Excitatory amino acids and central synaptic transmission. Trends in Pharmacol Sci 5:373-376.

Young EF, Ralston E, Blake J, Ramachandran J, Hall ZW, Stroud RW (1985) Topological mapping of acetylcholine receptor. Evidence for a model with five transmembrane segments and a cytoplasmic $\mathrm{COOH}-$ terminal peptide. Proc Natl Acad Sci USA 82:626-630. 